\title{
Design of the Reverse Logistics Network of New Energy Vehicle Waste Power Batteries
}

\author{
Longyu $\mathrm{He}^{1^{*}}$ \\ ${ }^{1}$ School of Economics, Wuhan University of Technology, Wuhan, China
}

\begin{abstract}
While making an optimistic estimate of the development prospects of new energy vehicles, this article pays attention to the problem of waste power batteries for new energy vehicles. Based on the theory of circular economy, waste batteries reverse logistics location factors and site selection methods, we propose waste power batteries In the design of the reverse logistics network, based on the recycling path of the used power battery reverse logistics network, two recycling modes of the used power battery reverse logistics network are proposed. Based on the location method and recycling mode, a reverse logistics network for the used power battery of new energy vehicles can be constructed.
\end{abstract}

\section{Introduce}

With the development of the global economy, the price of international oil has fluctuated sharply in recent years, and the amount of oil storage has been declining. Due to the need to protect the earth and save energy, all countries are looking for new energy sources to reduce their dependence on fossil energy. Under this background, the development of new energy vehicles is advancing by leaps and bounds, but while enjoying the benefits of new energy vehicles, its development is also facing an inevitable problem: the disposal of waste power batteries ${ }^{[1]}$

The life cycle of waste power batteries is usually 3 years. If they are not handled properly, the heavy metals such as cobalt and copper will have a great negative impact on the environment. ${ }^{[2]} \mathrm{A}$ waste power battery is enough to pollute thousands of hectares of land. The research on recycling and reverse logistics network of used automobile power batteries is of great practical significance.

\section{The basic theory of the reverse logistics network of used power batteries}

\subsection{Circular economy theory}

With the development and progress of science and technology, people are increasingly exploiting and utilizing natural resources, and the problems of environmental pollution and resource consumption have become increasingly apparent. If we continue to develop in accordance with traditional economic methods, it will inevitably lead to the deterioration of the natural environment and the deterioration of resources
Exhausted, so people began to seek a new economic development method that can develop sustainably, and circular economy was born ${ }^{[3]}$.

Circular economy requires products to produce as little waste as possible in the production and consumption process, so that resources can be recycled. The advantage of circular economy is that it can optimize the disposal of waste resources and achieve the goal of recycling and sustainable development of social resources. Figure 1 is a circular economy operation diagram.

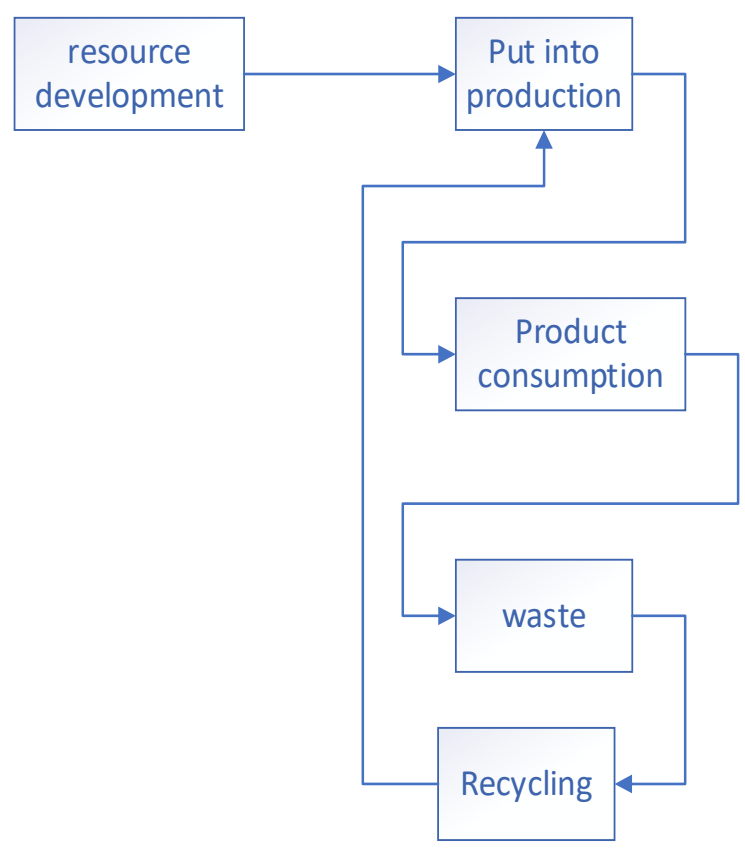

Figure 1 Operational Diagram of Circular Economy

Reverse logistics has promoted the development of circular economy. In forward logistics, items with potential use value are recycled, reused, and 
remanufactured. Among them, valuable substances are re-entered into the market for sale, and items with no value will be transported to the waste treatment center for filling. Buried or incinerated. On the other hand, only by constructing an efficient reverse logistics recovery network can we promote the fast and good sustainable development of circular economy. Therefore, the necessary conditions for the realization of circular economy in reverse logistics are complementary to each other.

\subsection{Site selection factors for reverse logistics of used batteries}

When constructing a reverse logistics network for scrapped power batteries for electric vehicles, it is necessary to follow the corresponding site selection principles, combine the basic characteristics of the reverse network for used power batteries, and put forward the factors that need to be considered for the used battery recycling system from the social, economic.

Social factors include market demand and policies and regulations. The consumption area is the beginning of the entire reverse logistics. The market share of electric vehicles in the consumption area is one of the important factors that determine the amount of reverse logistics recovery. ${ }^{[4]}$ At the same time, policies and regulations are another factor that cannot be ignored in the construction of a reverse logistics system. Comparison of local land use When it is difficult and the land price is relatively high, it is very beneficial to the establishment of a logistics network if it can obtain government support.

Economic factors include infrastructure investment and traffic conditions. When constructing a reverse logistics network for waste batteries of electric vehicles, it is first necessary to invest in the construction and operation of various node facilities, including the purchase of raw materials, land leases, and labor costs. At the same time, whether the transportation is convenient or not is an important factor that affects the efficient operation of the entire reverse logistics. Whether the transportation between the recycling center, recycling testing center, processing center, and waste disposal center is convenient or not directly affects the operating efficiency of the entire reverse logistics recycling system.

Environmental factors include the natural environment and the business environment. When selecting sites for each node, it is important to examine the bearing capacity of the local foundation, which is helpful to avoid inappropriate terrain. At the same time, when constructing a reverse logistics network, in order to avoid People's normal life is disturbed, and the impact of the business environment must be considered when selecting facilities at the beginning.

The influencing factors of site selection are shown in Figure 2.

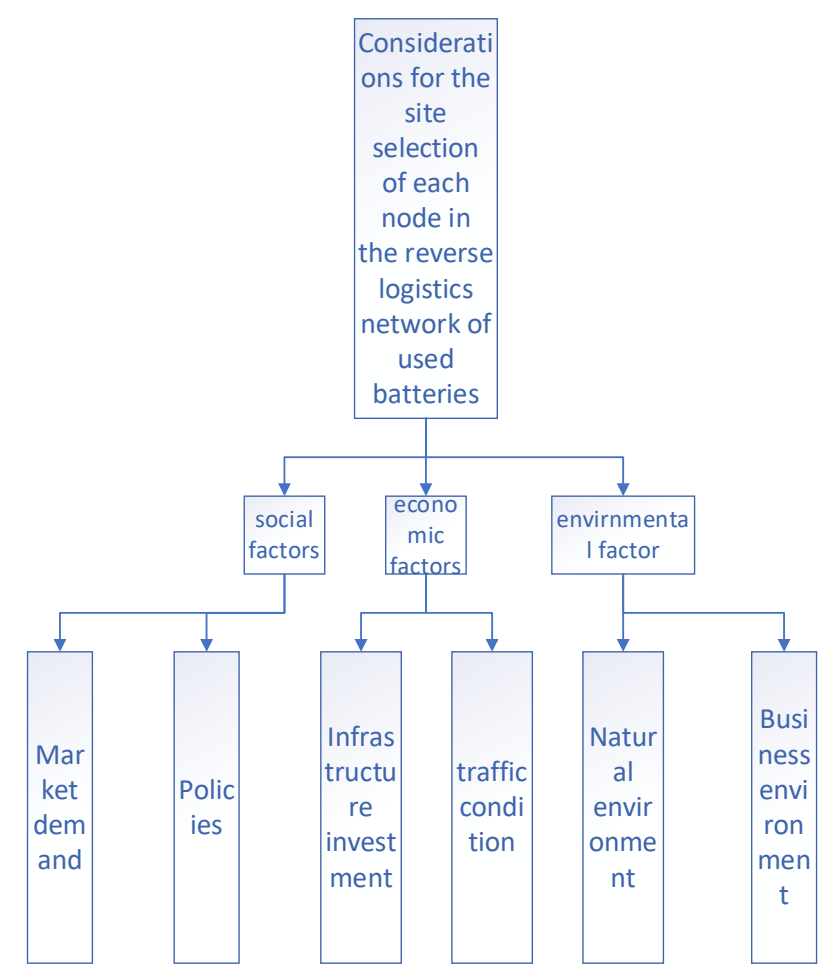

Figure 2 Factors affecting site selection

\subsection{Site selection method for reverse logistics of used batteries}

In industrial engineering, system science and other fields, there are a lot of problems that need to be optimized. If a deterministic model is used to solve the problem, there will be large errors. In order to avoid this problem, the uncertain programming method should be adopted. When solving uncertain problems, fuzzy programming methods are mostly used to solve them, which is equivalent to the equivalent conversion of uncertain models.

Suppose $x$ is the decision variable, $\delta$ is the fuzzy variable, $f(x, \delta)$ is the objective function, $g_{j}(x, \delta) \leq 0$ is the constraint condition, then the general formula of fuzzy programming is shown in formula (1)

$$
\begin{aligned}
& \min f(x, \delta) \\
& \text { st. } \\
& g_{i}(x, \delta) \leq 0
\end{aligned}
$$

The fuzzy variables in the objective function and constraint conditions make $f(x, \delta)$ and $g_{j}(x, \delta)$ ambiguous. Therefore, a fuzzy chance constrained programming model is needed to solve the problem. The main idea of the fuzzy chance constrained programming model is to propose an optimal confidence level that can make the objective function and constraint conditions reach the optimal level. The fuzzy chance-constrained programming model is shown in formula (2)

$$
\begin{aligned}
& \begin{array}{c}
\min \bar{f}(x, \delta) \\
s t \\
\operatorname{pos}(f(x, \delta) \leq \bar{f}) \geq a
\end{array} \\
& \text { pos }\left(g_{j}(x, \delta) \leq 0\right) \geq \beta_{j}
\end{aligned}
$$


Where $j=1,2, \ldots \ldots \mathrm{q}, \quad a$ represents the confidence level of the objective function, $\beta_{j}$ represents the confidence level of pos $\left(g_{j}(x, \delta) \leq 0\right) \geq \beta_{j}$.

At the same time, the triangular fuzzy number is introduced to clarify the fuzzy chance constraints. Among them, the fuzzy number is $\stackrel{\infty}{\alpha}_{i}$, and its membership function is $\mu(x)$.

$$
\begin{gathered}
\operatorname{pos}\left(\tilde{\alpha}_{i} \leq \mathrm{Z}\right)=\operatorname{pos}\left\{\mu_{d}^{\infty} / x \in R, \mathrm{Z} \geq x\right\} \\
\left\{\operatorname{pos}\left(\tilde{\alpha}_{i} \geq \mathrm{Z}\right)=\operatorname{pos}\left\{\mu_{d}^{\circ} / x \in R, \mathrm{Z} \leq x\right\}\right. \\
\operatorname{pos}\left(\alpha_{i}=\mathrm{Z}\right)=\mu_{d}^{\sim}(\mathrm{Z})
\end{gathered}
$$

The site selection method of used battery reverse logistics can determine the site selection interval and possible options of each node of the used battery reverse logistics network. Combined with the used battery reverse logistics location factor, the overall optimal plan of each node in the network can be determined.

\section{Recycling of used power batteries in the reverse logistics network}

\subsection{Recycling path of used power battery reverse logistics network}

There are two types of recycled waste batteries: one is that the capacity of the battery is no longer sufficient for the normal driving of electric vehicles, but it can be used in cascades, such as energy storage that can be used for electricity; the other is that the battery capacity is relatively severely depleted, which makes the battery It cannot be used normally and cannot satisfy the normal driving of electric vehicles. At this time, the only way to recycle the battery is to recover its valuable resources. The battery recycling path is shown in Figure 3.

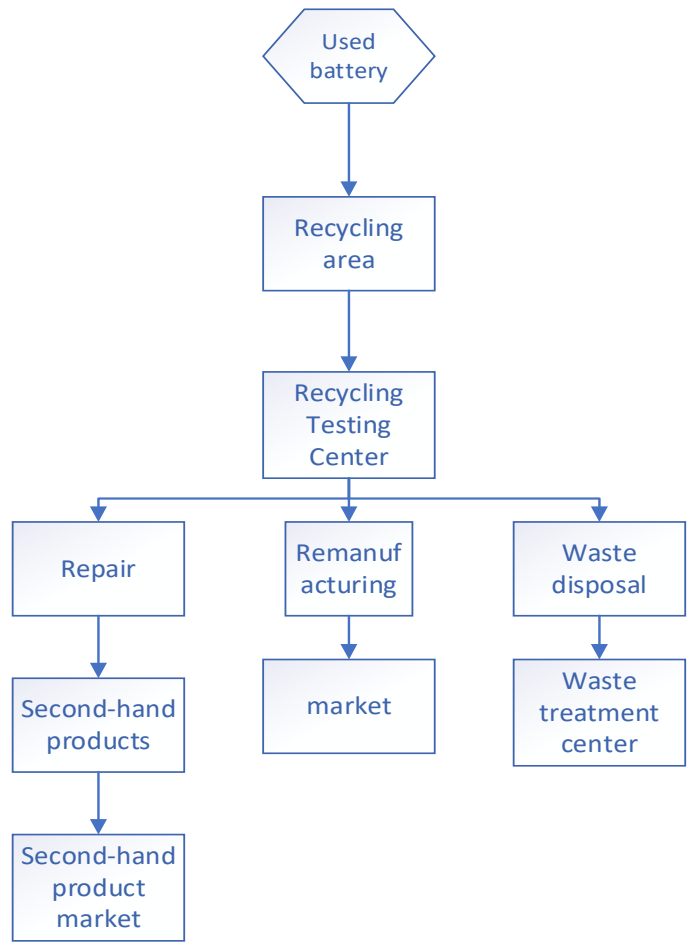

Figure 3 Battery recycling path diagram
Repair: transport the recycled used power batteries to the recycling testing center for testing. For batteries with less damage, parts can be replaced or simply repaired, and then such batteries can be put into the second-hand market for sale.

Remanufacturing: After testing by the recycling and testing center, used batteries with severe damage can be transported to the processing center for remanufacturing. The processing center is mainly divided into two steps: disassemble and process the modules that can be used by the battery, and reassemble these modules into other batteries; the battery materials remaining after disassembly can be chemically refined. Extract metals such as lithium and iron, and then sell these metals to battery manufacturers.

Disposal treatment: The parts that cannot be restored to use value through repair and remanufacturing will be transported to waste disposal sites for destruction or landfill to ensure that they will not be randomly discarded, thereby reducing environmental pollution.

The process of remanufacturing and reusing waste power batteries can tap the potential use value of power batteries, which not only saves resources, but also protects the environment.

\subsection{Recycling mode of the reverse logistics network of used power batteries}

In the recycling process, the battery manufacturer can be recycled as a recycling company, it can be recycled by entrusting an electric car dealer, or it can be outsourced to a third-party logistics company. Therefore, according to the existing organizational model of power batteries, this article constructs a consortium jointly responsible for the operation model and a third-party recycling model.

For the joint responsibility operation model of the consortium, due to the small power of a single enterprise, in the actual implementation process, there will be situations where funds cannot be returned in time, and the amount of recovery cannot meet the daily needs of the enterprise. The operating model of joint responsibility of the consortium came out in this context. Participants in this model include power battery manufacturers, electric car rental companies, and electric car dealers. The three formed a strategic alliance and signed an agreement to establish a waste battery recycling system. When there are used batteries to be recycled, the members of the alliance will actively cooperate to complete the recycling of used batteries.

The main feature of this model is that it can mobilize all members of the industry so that they have the responsibility to cooperate with the recycling of power batteries; it has a strong influence, wide coverage, and independent operation. This model is highly adaptable and can be applied to battery recycling in different regions of the country.

Under normal circumstances, the power battery will be sold to consumers as the supporting equipment of electric vehicles. Therefore, like the entire electric vehicle supporting system, consumers also own the 
ownership of the power battery. Under this sales model, power battery manufacturers can also contribute to the recycling of batteries through electric vehicle dealers. For example, they can establish a sales network through dealers to recycle used power batteries.

In this recycling network, it starts with consumers, who send the scrapped power batteries to the electric car sales outlets in their area. ${ }^{[5]}$ After that, the electric car dealers fulfill the cooperation they have signed with the battery manufacturers. According to the agreement, the used batteries sent by consumers will be transferred to the battery manufacturer at the price agreed by both parties. Then, the battery manufacturer will hand over the used batteries to the battery manufacturer for professional treatment of the used batteries. The advantage of this method of processing is that the battery can be professionally processed, and the battery manufacturer has achieved the goal of continuing to use the available metal in the recycled waste battery for battery production.

The consortium is jointly responsible for the recovery flow chart of the operating mode as shown in Figure 4.

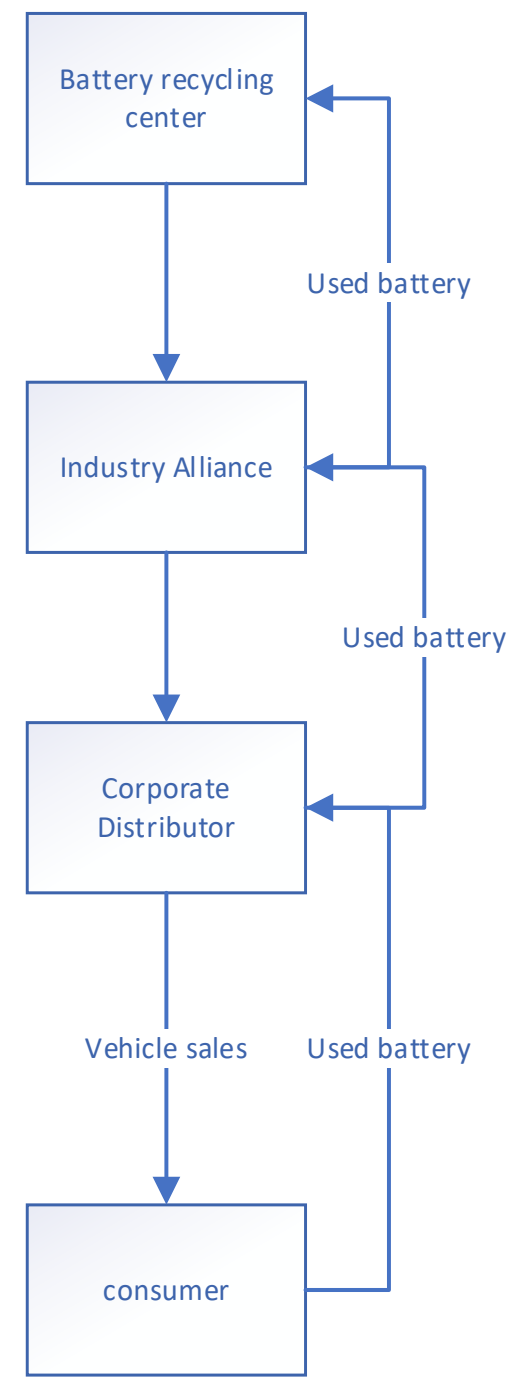

Figure 4 Consortium’s joint responsibility operating model

For the third-party recycling model, due to the different scales and comprehensive strengths of power battery manufacturers, some manufacturers can neither build their own recycling centers nor join a strategic alliance due to their own reasons. At this time, they can entrust the recycling business to a third party. Recycling companies only need to pay a certain fee at that time. In the entire recycling process, the recycling of used batteries is carried out by a third party, which not only makes full use of social resources for comprehensive configuration, realizes economies of scale, but also satisfies the company's recycling business.

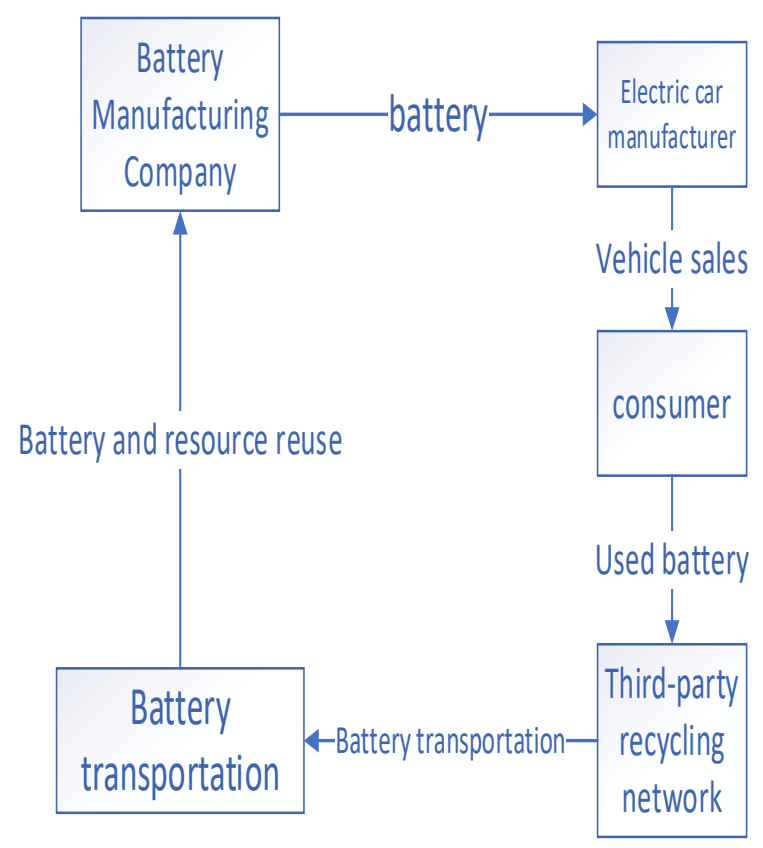

Figure 5 Third-party recycling model

\section{References}

1. Saeed Kargar,Mohammad Pourmehdi,Mohammad Mahdi Paydar. Reverse logistics network design for medical waste management in the epidemic outbreak of the novel coronavirus (COVID-19)[J]. Science of the Total Environment,2020,746.

2. Gan Junwei, Luo Li, Kou Ran. Research progress and trend of sustainable reverse logistics network design [J]. Control and Decision, 2020, 35(11): 2561-2577.

3. Wang Li. Analysis of the Research on the Reverse Logistics Network Planning of Waste Electronic Products[J]. Computer Products and Circulation, 2020(11):96.

4. Geng Liyan, Zhang Nan, Zhang Zhanfu. Reverse logistics network planning and design for recycling lead-acid batteries for electric bicycles[J]. Logistics Technology, 2020, 39(08): 8-11.

5. Liang Qianqian, Wang Gang, Wang Yaru. Network optimization design for reverse logistics of used batteries[J]. Modern Information Technology, 2020,4(11):116-117+12 